6. Teuma, M. M., Ambang, Z., Ekobena, F. H. P., Tabi, C. B. and Kofane, T. C., Stochastic electrical behavior of splina liquid chlorophyll drink. Indian J. Sci. Technol., 2018. 11(12), doi:10.17485/ijst/2018/v11i12/120086.

7. Gounar, I. I., Panishkmine, L. A. and Tihonov, F. P., Activité bioélectrique du tournesol et de la tomate sur quelques types de pathogénéité. J. Acad. Agric. Moscou., 1974, 5, 3-8.

8. Teuma, M. M., Ambang, Z., Ekobena, F. H. P., Tabi, C. B. and Kofane, T. C., Study of the passive electrical properties of tomato tissues after infection and treatment by fongicide. Indian J. Sci. Technol., 2017, 10(26); doi:10.17485/ijst/2017/v10i27/112835.

9. Teuma, M. M., Ambang, Z., Tabi, C. B., Ekobena, F. H. P. and Kofane, T. C., Study of the photo-electric behavior of Spinacia oleracea. Indian J. Sci. Technol., 2018, 11(22).

10. Huffman, D., A method for the construction of minimumredundancy codes. Proc. IRE, 1952, 40(9), 1098-1101; doi: 10.1109/JRPROC.1952.2738.

11. Sellers, P. J., Canopy reflectance, photosynthesis and transpiration. Int. J. Remote Sensing, 1985, 6(8), 1335-1372.

12. Mallick, N. and Mohn, F. H., Use of chlorophyll fluorescence in metal-stress research: a case study with the green microalga Scenedesmus. Ecotoxicol. Environ. Saf., 2003, 55, 64-69.

13. Ambang, Z., Amougou, A. and Gorthakov, V. V., Action des pesticides sur les propriétés électriques passives des tissus de la pomme de terre. Ann. Fac. Sci, Univ. Yaounde I, Serie; SC. de la Nat. et de la vie, 2003, 25(N-2), 75-78.

ACKNOWLEDGEMENT. We thank Nkolo Laure-Martine for assistance.

\section{Infusing microbial consortia for enhancing seed germination and vigour in pigeonpea (Cajanus cajan (L.) Millsp.)}

\author{
K. Raja ${ }^{1, *}$, R. Anandham ${ }^{2}$ and \\ K. Sivasubramaniam ${ }^{3}$ \\ ${ }^{1}$ Department of Seed Science and Technology, \\ Tamil Nadu Agricultural University, Coimbatore 641 003, India \\ ${ }^{2}$ Department of Agricultural Microbiology, \\ Tamil Nadu Agricultural University, Coimbatore 641 003, India \\ ${ }^{3}$ Agricultural College and Research Institute, \\ Tamil Nadu Agricultural University, Kudumiyanmalai 622 104, India
}

Use of plant growth promoting bacteria for seed treatment is in trend nowadays as it is beneficial to the plants and environment. But, carrier-based inoculants have short shelf life and difficult to use for large quantities of seed. Therefore, in the present study we used liquid microbial cultures for seed infusion in pigeon-

\footnotetext{
*For correspondence. (e-mail: kraja_sst@rediffmail.com)
}

pea and assessed their compatibility with seed treating chemicals. The results showed that the soaking of pigeonpea seeds in liquid cultures like pink pigmented facultative methylotroph (PPFM)@1:100 dilution for 3 h or Rhizobium or phosphobacteria @ 1 :50 dilution for $4 \mathrm{~h}$ have showed increased germination and vigour. In the microbial infused seeds, Rhizobium $\left(13 \times 10^{4} \mathrm{cfu}^{-1}\right.$ of seed) and phosphobacteria $(20 \times$ $10^{4} \mathrm{cfu}^{-1}$ of seed) populations observed, were slightly reduced during three months storage. Nevertheless, the population was drastically reduced in PPFM $\left(11 \times 10^{4}\right.$ to $2 \times 10^{4} \mathrm{cfu}^{-1}$ of seed $)$. Conversely, PPFM has performed better in seed quality enhancement amongst cultures. Also, consortia of Rhizobium@ $1: 50$ dilution + PPFM@1:100 dilution $(1: 1)$ for $3 \mathrm{~h}$ increased seed vigour with better microbial populations $\left(14 \times 10^{4}\right.$ and $2 \times 10^{4} \mathrm{cfu} \mathrm{g}^{-1}$ of seed). Also, seed infusion with PPFM liquid culture $@ 1: 100$ dilution for $3 \mathrm{~h}$ followed by polymer coating $@ 5 \mathrm{ml} \mathrm{kg}^{-1}+$ carbendazim treatment $@ 2 \mathrm{~g} \mathrm{~kg}^{-1}$ of seed recorded increased germination and vigour with the PPFM population of $1 \times 10^{4} \mathrm{cfu}^{-1}$ of seed.

Keywords: Pigeonpea, PPFM, phosphobacteria, Rhizobium, seed germination, vigour.

SEED is an important input in agriculture and the quality of the seed alone contributes $20 \%$ yield increase. Quality of the seed can be improved by pre-sowing seed management techniques. Among the pre-sowing seed management techniques, seed treatment with the plant growth promoting bacteria (PGPB), viz. biofertilizers or biocontrol agents, is one of the important methods by which the yield can be improved by $5 \%$ to $30 \%$ (ref. 1 ). Use of these effective microorganisms as a pre-sowing seed treating agent is considered to be ecologically sound and beneficial to both seed and environment. Application of inoculum to the seeds of host plants is still in vogue with carrier-based bacterial inoculants ${ }^{2}$. Sometimes, in order to improve stickiness on the seed, adhesive is added $^{3}$. However, carrier-based inoculants have a short shelf life, poor quality and the production and application procedure for most of these inoculants were found to be time consuming and difficult when used for large quantities of seed.

Alternatively, liquid inoculants were developed for seed treatment as they are easy to use, spread well, mix easily and need no additional water supply ${ }^{4}$. The liquid rhizobial inoculant for pea and lentils resulted in yield equal to or better than those obtained for the peat inoculant $\mathrm{t}^{5}$. However, treating the pulses seed in liquid culture will lead to cracking injury which ultimately affects the storability. Therefore, care should be taken to treat the seed with liquid inoculants. Also, the fungicides are nonspecific in their lethal action against the organisms. The responses of seed treating chemicals such as captan, thiram, mancozeb, ridomil, benlate and vitavax, etc. have been studied on the survival of Rhizobium and 


\section{RESEARCH COMMUNICATIONS}

Bradyrhizobium inoculated seeds of some leguminous crops $^{6,7}$. Therefore, our study was conducted to infuse the liquid microbial cultures for enhancing seed germination and vigour in pigeonpea and also to know the effect of seed treating chemicals on the survival of the inoculants.

Pigeonpea variety, $\mathrm{CO}(\mathrm{RG}) 9$ seeds were collected from the Department of Pulses, Tamil Nadu Agricultural University, Coimbatore, India and dried well for the purpose of microbial treatments. The bacterial strains, viz. Methylobacterium (pink pigmented facultative methylotroph (PPFM)), Rhizobium and phosphobacteria were obtained from the Department of Agricultural Microbiology, Agricultural College and Research Institute, Madurai, India. The strains were cultured in NFb (nitrogen fixing bacteria) nutrient broth and ammonium mineral salts medium supplemented with $0.5 \%$ methanol. The liquid based bioinoculant formulations were prepared for treating the seeds.

The liquid cultures were diluted at various concentrations, viz. $1: 1,1: 10,1: 50$ and $1: 100$ dilutions along with undiluted one. Then, the pigeonpea seeds were soaked in these culture concentrations at different time durations, viz. 2, 3, 4 and $5 \mathrm{~h}$ with half of the culture volume i.e. $1: 1.5$ ratio $(\mathrm{v} / \mathrm{v})$ to avoid soaking injury to the seeds caused by excess water. Later, the seeds were shade dried to the original moisture content. The germination test was conducted as per the ISTA ${ }^{8}$ procedure and evaluated. The speed of germination was also assessed during the germination test ${ }^{9}$. Five randomly selected seedlings in each treatment were measured for their lengths and mean was arrived. After standardization of the concentrations, the freshly collected pigeonpea seeds were inoculated with liquid microbial cultures to assess the storability of the seeds as per the treatments, such as $\mathrm{T}_{1}$ - control; $\mathrm{T}_{2}$ - seed soaking in Rhizobium @ 1:50 dilution for $3 \mathrm{~h} ; \mathrm{T}_{3}$ - seed soaking in phosphobacteria @ 1:50 dilution for $3 \mathrm{~h}$ and $\mathrm{T}_{4}$ - seed soaking in PPFM (a) $1: 100$ dilution for $3 \mathrm{~h}$. The seeds were shade dried to the original moisture content and evaluated for their initial germination. The seeds were then packed in polythene bags and stored under ambient condition for three months. After the storage period, the seeds were evaluated for their viability and vigour. Also, microbial populations in the seeds during initial and after three months storage were assessed. For this, the seeds were soaked in the sterile water and allowed in arbitrary shaker for about one hour. The serial dilutions were prepared and inoculated in the respective medium.

In another experiment, different microbial cultures, namely Rhizobium, phosphobacteria and PPFM were prepared and diluted as standardized in the earlier experiment likeRhizobium@1:50,phosphobacteria@1:50 and PPFM@1:100 concentrations. The microbial consortia were then prepared by mixing the different cultures at $1: 1$ or $1: 1: 1$ ratio. The seeds were soaked in the microbial consortia uniformly for $3 \mathrm{~h}$ in half of the volume by following the treatment schedule, which was: $\mathrm{T}_{1}-$ control; $\mathrm{T}_{2}-$ seed soaking in water; $\mathrm{T}_{3}-$ seed soaking in Rhizobium@1:50 dilution; $\mathrm{T}_{4}$ - seed soaking in phosphobacteria@1:50 dilution; $\mathrm{T}_{5}$ - seed soaking in PPFM @ 1:100 dilution; $\mathrm{T}_{6}$ - seed soaking in Rhizobium @ 1:50 dilution+phosphobacteria@1:50 dilution (1:1); $\mathrm{T}_{7}$ - seed soaking in Rhizobium @ 1:50 dilution + PPFM (a) $1: 100$ dilution $(1: 1)$ and $\mathrm{T}_{8}-$ seed soaking in Rhizobium@1:50 dilution+phosphobacteria@1:50 dilution+PPFM@1:100 dilution $(1: 1: 1)$. The seeds were dried to the original moisture content. The germination, vigour and microbial populations were assessed.

In addition, the effect of seed treating chemicals on the survival of microbes in pigeonpea seeds were assessed by infusing them with different liquid microbial cultures for $3 \mathrm{~h}$ in half of the volume. These bio-inoculated seeds were shade dried to the original moisture content. Later, they were treated with different chemicals as per the following treatment schedule: $\mathrm{T}_{1}-$ control; $\mathrm{T}_{2}-$ seed soaking in Rhizobium@1:50 dilution; $\mathrm{T}_{3}$ - seed soaking in Rhizobium @1:50 dilution+polymer coating@ $5 \mathrm{ml} \mathrm{kg}^{-1}$ of seed; $\mathrm{T}_{4}$ - seed soaking in Rhizobium @ $1: 50$ dilution + carbendazim seed treatment@2 $\mathrm{g} \mathrm{kg}^{-1}$ of seed; $\mathrm{T}_{5}$ - seed soaking in Rhizobium@1:50 dilution+polymer coating@5 ml kg ${ }^{-1}+$ carbendazim seed treatment@2 $\mathrm{g} \mathrm{kg}^{-1}$ of seed; $\mathrm{T}_{6}-$ seed soaking in phosphobacteria@1:50 dilution; $\mathrm{T}_{7}$ - seed soaking in phosphobacteria@1:50 dilution+polymer coating@5ml $\mathrm{kg}^{-1}$ of seed; $\mathrm{T}_{8}$ - seed soaking in phosphobacteria@ 1:50 dilution + carbendazim seed treatment@2 $\mathrm{g} \mathrm{kg}^{-1}$ of seed; $\mathrm{T}_{9}$ - seed soaking in phosphobacteria@1:50 dilution+ polymer coating@5 ml kg-1 + carbendazim seed treatment@2 $\mathrm{g} \mathrm{kg}{ }^{-1}$ of seed; $\mathrm{T}_{10}$ - seed soaking in PPFM@1:100 dilution; $\mathrm{T}_{11}$-seed soaking in PPFM @ $1: 100$ dilution + polymer coating@ $9 \mathrm{ml} \mathrm{kg}^{-1}$ of seed; $\mathrm{T}_{12}$-seed soaking in PPFM @ 1:100 dilution + carbendazim seed treatment @ $2 \mathrm{~g} \mathrm{~kg}^{-1}$ of seed and $\mathrm{T}_{13}-$ seed soaking in PPFM@1:100 dilution + polymer coating@ $5 \mathrm{ml} \mathrm{kg}^{-1}$ of seed + carbendazim seed treatment@ $2 \mathrm{~g} \mathrm{~kg}^{-1}$ of seed. The treated seeds were stored for a week and evaluated for germination and vigour. Microbial populations in the treated seeds were also assessed. In this regard, the treated seeds were first washed with sterile water for about four to five times to remove the chemicals adhering on the surface of the seeds. Later, they were soaked in the sterile water and allowed in arbitrary shaker for about one hour. The serial dilutions were prepared and inoculated in the respective medium.

The data collected were subjected to statistical analy$\operatorname{sis}^{10}$ and the critical difference values were calculated at $5 \%$ probability level.

The results obtained showed that the pigeonpea seeds soaked in liquid cultures displayed significant increase in germination and vigour. In case of PPFM, highest germination $(98 \%)$ was recorded in the seed soaking treatment with $1: 100$ dilution for $3 \mathrm{~h}$. However, seeds soaked in 


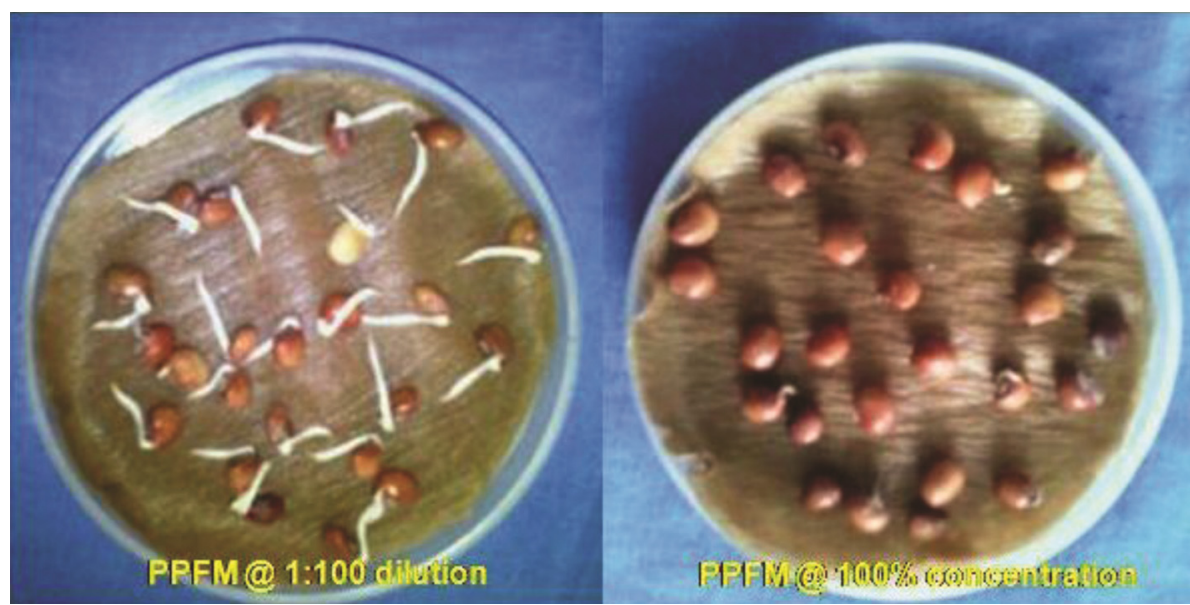

Figure 1. Effect of pink pigmented facultative methylotroph liquid culture on speed of seed germination in pigeonpea.

Table 1. Effect of seed infusion with pink pigmented facultative methylotroph (PPFM) liquid culture on germination and vigour in pigeonpea

\begin{tabular}{|c|c|c|c|c|c|c|c|c|c|c|c|c|c|c|c|}
\hline \multirow[b]{2}{*}{ Treatments } & \multicolumn{5}{|c|}{ Seed germination $(\%)$} & \multicolumn{5}{|c|}{ Speed of germination } & \multicolumn{5}{|c|}{ Seedling length (cm) } \\
\hline & $2 \mathrm{~h}$ & $3 \mathrm{~h}$ & $4 \mathrm{~h}$ & $5 \mathrm{~h}$ & Mean & $2 \mathrm{~h}$ & $3 \mathrm{~h}$ & $4 \mathrm{~h}$ & $5 \mathrm{~h}$ & Mean & $2 \mathrm{~h}$ & $3 \mathrm{~h}$ & $4 \mathrm{~h}$ & $5 \mathrm{~h}$ & Mean \\
\hline Untreated control & 91 & 91 & 91 & 91 & 91.0 & 7.6 & 7.6 & 7.6 & 7.6 & 7.6 & 24.6 & 24.6 & 24.6 & 24.6 & 24.6 \\
\hline Seed soaking in water & 86 & 92 & 90 & 88 & 89.0 & 5.6 & 7.2 & 6.8 & 8.8 & 8.1 & 22.9 & 24.7 & 26.0 & 24.7 & 24.6 \\
\hline Seed soaking in PPFM@100\% concentration & 62 & 76 & 76 & 74 & 72.0 & 8.2 & 7.3 & 5.5 & 6.9 & 6.9 & 31.3 & 27.6 & 24.8 & 22.8 & 26.6 \\
\hline Seed soaking in PPFM@1:1 dilution & 80 & 82 & 72 & 72 & 76.5 & 8.2 & 7.7 & 6.7 & 7.5 & 7.5 & 32.0 & 30.7 & 33.8 & 30.3 & 31.7 \\
\hline Seed soaking in PPFM@1:50 dilution & 97 & 86 & 84 & 86 & 88.3 & 9.6 & 10.9 & 10.2 & 10.2 & 10.2 & 32.5 & 33.5 & 32.3 & 30.8 & 32.2 \\
\hline Seed soaking in PPFM@1:100 dilution & 97 & 98 & 94 & 90 & 94.6 & 12.3 & 13.3 & 13.3 & 10.2 & 12.3 & 32.1 & 35.3 & 32.6 & 31.0 & 32.7 \\
\hline \multirow[t]{2}{*}{ Mean } & 85.9 & 86.9 & 83.7 & 81.7 & 84.6 & 8.5 & 9.1 & 8.5 & 8.6 & 8.7 & 29.7 & 29.7 & 29.7 & 28.0 & 29.2 \\
\hline & \multicolumn{2}{|c|}{ Treatment } & \multicolumn{2}{|c|}{ Duration } & $\mathrm{T} \times \mathrm{D}$ & \multicolumn{2}{|c|}{ Treatment } & \multicolumn{2}{|c|}{ Duration } & $\mathrm{T} \times \mathrm{D}$ & \multicolumn{2}{|c|}{ Treatment } & \multicolumn{2}{|c|}{ Duration } & $\mathrm{T} \times \mathrm{D}$ \\
\hline Standard error deviation (SEd) & \multicolumn{2}{|c|}{1.9} & \multicolumn{2}{|c|}{1.5} & 3.9 & \multicolumn{2}{|c|}{0.03} & \multicolumn{2}{|c|}{0.02} & 0.05 & \multicolumn{2}{|r|}{1.2} & \multicolumn{2}{|c|}{0.9} & 2.4 \\
\hline Critical difference $(\mathrm{CD}, P=0.05)$ & \multicolumn{2}{|c|}{3.9} & \multicolumn{2}{|l|}{2.9} & 7.9 & \multicolumn{2}{|c|}{0.05} & \multicolumn{2}{|c|}{0.04} & 0.10 & \multicolumn{2}{|r|}{2.5} & \multicolumn{2}{|c|}{ NS } & NS \\
\hline
\end{tabular}

*NS, Nonsignificant.

undiluted (100\% concentration) and the other diluted (1:1 and $1: 10$ dilutions) cultures showed drastic reduction in germination and even lesser than the control (Table 1). The extended period of soaking, viz. 4 and $5 \mathrm{~h}$, too affected the germination in pigeonpea seeds. Speed of germination (13.3) and seedling length $(35.3 \mathrm{~cm})$ were also higher when the seeds were soaked in PPFM culture (a) $1: 100$ dilution for $3 \mathrm{~h}$ when compared with control or undiluted culture (Figures 1 and 2). However, the higher culture concentrations and long soaking durations affected the seed vigour considerably. Similarly highest germination (100\%), speed of germination (10.9) and seedling length $(28.0 \mathrm{~cm})$ were recorded in the treatment with $1: 50$ diluted Rhizobium liquid culture for $4 \mathrm{~h}$ (Table 2 ). The germination and vigour declined, whereas neither the culture concentration nor soaking period increased. Nevertheless, seeds soaked in undiluted culture for $5 \mathrm{~h}$ showed antagonistic effect on germination (67\%). Likewise, the phosphobacteria treated seeds showed highest germination (100\%), speed of germination (14.6) and seedling length $(29.3 \mathrm{~cm})$ at $1: 50$ dilution for $4 \mathrm{~h}$ (Table $3)$. The germination and vigour were affected at higher concentrations, i.e. undiluted and $1: 1$ diluted liquid cultures.

Among the cultures, PPFM performed better in increasing germination (98\%), speed of germination (8.8) and seedling length $(28.5 \mathrm{~cm})$ at $1: 100$ dilution for $3 \mathrm{~h}$ (Table 4). Also, no significant differences were observed in the germination and seedling vigour during the three months storage of these treated seeds. But the reduction in microbial population was noticed irrespective of the inoculants during seed storage. Phosphobacteria recorded the highest population during initial $\left(24 \times 10^{4} \mathrm{cfu} \mathrm{g}^{-1}\right.$ of seed) as well as three months storage $\left(20 \times 10^{4} \mathrm{cfu} \mathrm{g}^{-1}\right.$ of seed). PPFM recorded the population between $11 \times 10^{4}$ and $2 \times 10^{4} \mathrm{cfu} \mathrm{g}^{-1}$ of seed during initial and three months storage respectively. The available seed moisture might have supported the viability of the microorganisms in the seed. 
RESEARCH COMMUNICATIONS

Table 2. Effect of seed infusion with Rhizobium liquid culture on germination and vigour in pigeonpea

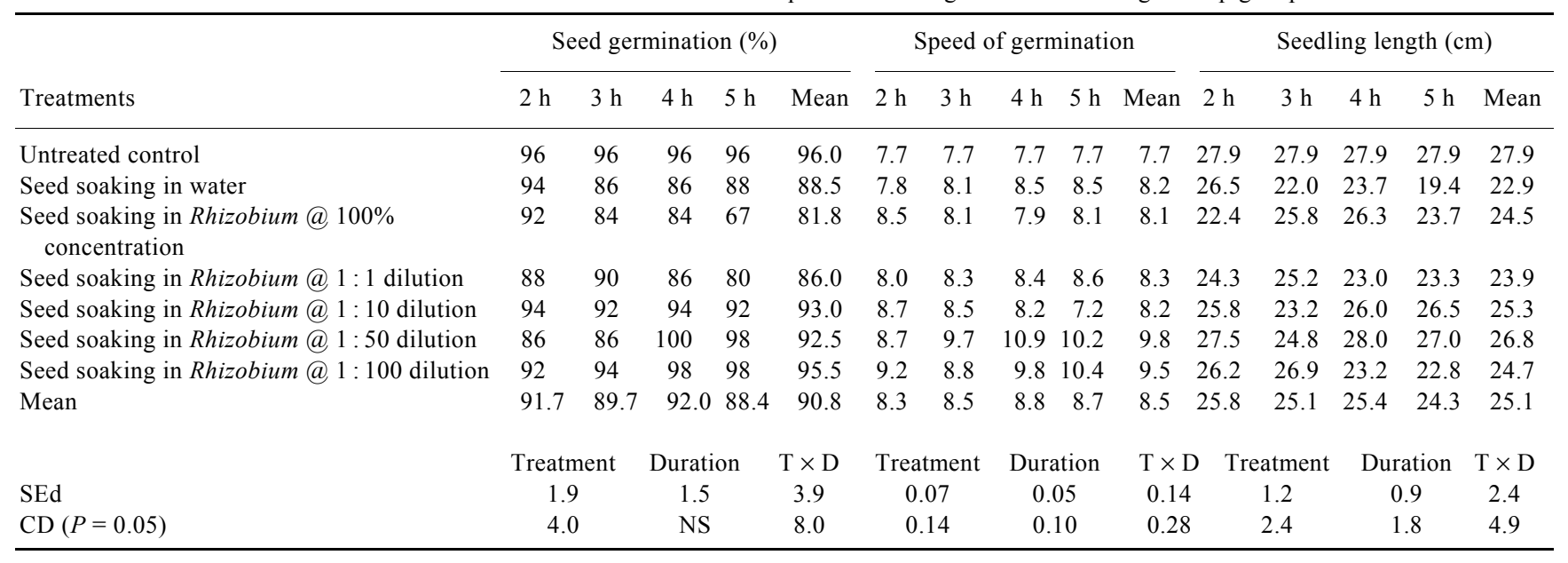

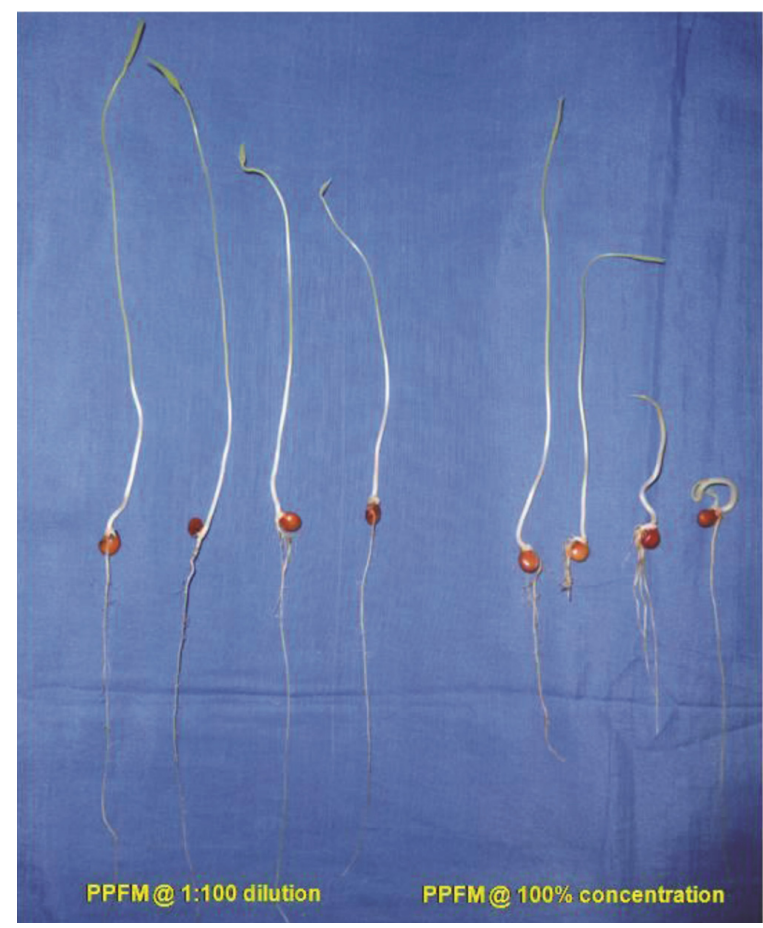

Figure 2. Effect of PPFM liquid culture on seedling vigour in pigeonpea.

Similarly, pigeonpea seeds showed positive response for the infusion of microbes as single or consortium cultures. Highest germination (98\%) was found in seed soaking treatment with PPFM liquid culture@1:100 dilution for $3 \mathrm{~h}$, which was on par with Rhizobium @ 1:50 dilution+PPFM@1:100 dilution (1:1) liquid cultures consortia (97\%). Speed of germination (11.0) and seedling length $(32.3 \mathrm{~cm})$ were also higher in these consortia treated seeds (Table 5). Microbial populations, i.e. $14 \times 10^{4}$ and $2 \times 10^{4} \mathrm{cfu} \mathrm{g}^{-1}$ of seed were observed in Rhizobium and PPFM treated seeds which might have contributed for the enhanced germination and vigour.
In addition, pigeonpea seed treatment with microbial cultures and chemicals showed that the PPFM liquid culture@1:100 dilution for 3h+polymer coating@ $5 \mathrm{ml} \mathrm{kg}^{-1}$ of seed + carbendazim seed treatment@2 g $\mathrm{kg}^{-1}$ of seed recorded increased germination (97\%), speed of germination (10.2) and seedling length $(29.7 \mathrm{~cm})$ than the control (Table 6). With respect to microbial population, the above treatment recorded PPFM population of $2 \times 10^{4} \mathrm{cfu} \mathrm{g}^{-1}$ of seed. Among the treatments, seed treatment with phosphobacteria $\left(24 \times 10^{4} \mathrm{cfu}^{-1}\right.$ of seed $)$ recorded the highest microbial population. Generally, polymer coating will not affect much the microbial population in the seed. However, the population was affected in the carbendazim treated seeds. Fortunately, polymer coating followed by carbendazim treatment recorded only a minimum reduction in the microbial population. This shows that the polymer coating acts as a barrier between the microbes and carbendazim.

Seed soaking in liquid microbial culture provides the benefit of penetration and survival in the seed. However, culture concentration and soaking duration are very important for getting the potential benefits. It was found that the PPFM had better synergistic effect on pigeonpea seed germination and seedling vigour among the cultures. The enhanced seed germination by seed coating or seed inoculum of methylotrophs has been recorded earlier ${ }^{11,12}$. Nkpwatt et al. ${ }^{13}$ found that the cell-free supernatant of the Methylobacterium bacterial culture stimulated germination, suggesting the production of a growth-promoting agent by the methylotroph. PPFM mediate cytokinin on germinating seeds ${ }^{14}$ and indole acetic acid (IAA) on increased seedling vigour ${ }^{15}$. Bakonyi et al. ${ }^{16}$ opined that there was a positive effect of PGPB on germination and growth through reasons of excreting phytohormones and enhancement of nutrient mobilization from the seed.

Consortia can also be considered to deliver the seeds with different kinds of microbes into the fields. Qureshi et al. ${ }^{17}$ found that the co-inoculation of Rhizobium and 


\section{RESEARCH COMMUNICATIONS}

Table 3. Effect of seed infusion with phosphobacteria liquid culture on germination and vigour in pigeonpea

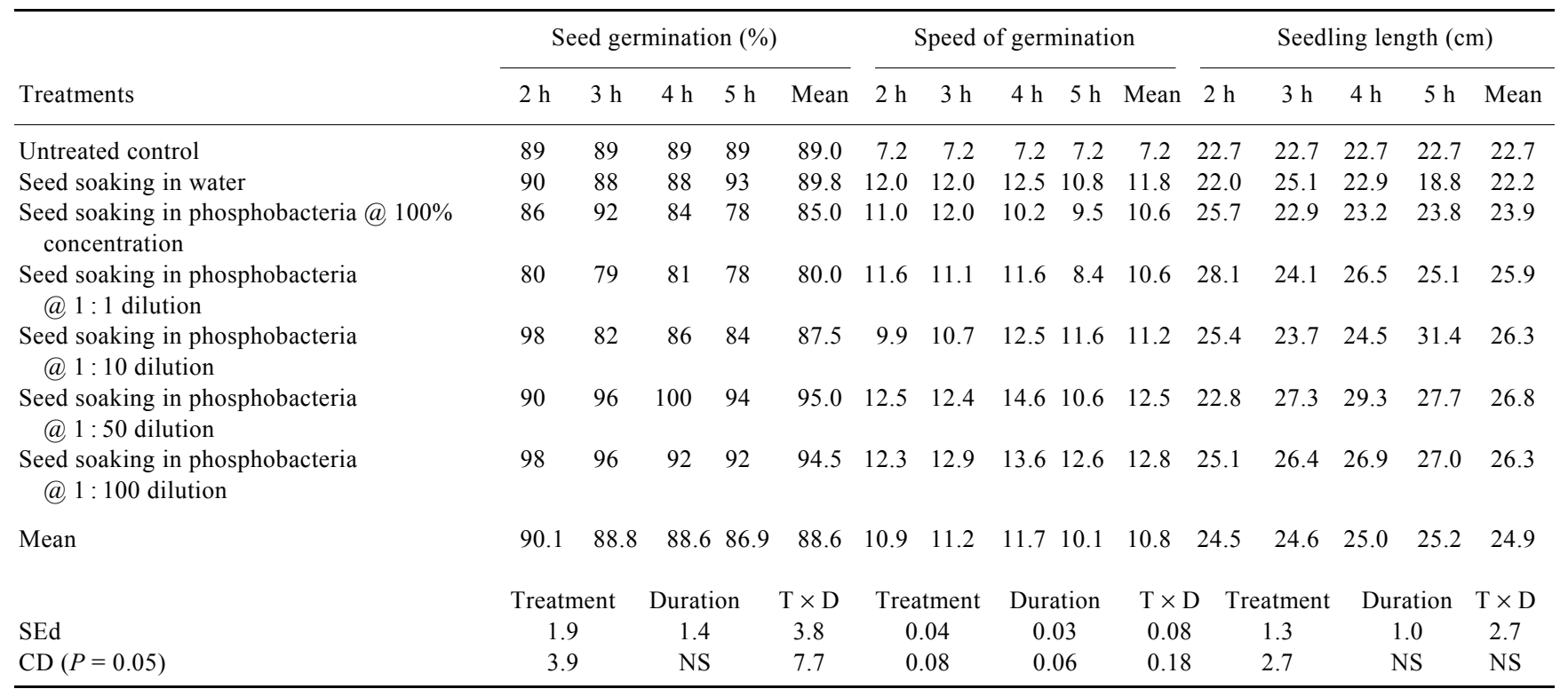

Table 4. Effect of seed infusion with liquid bio-inoculants on seed viability and microbial population in pigeonpea

\begin{tabular}{|c|c|c|c|c|c|c|c|c|c|c|c|}
\hline \multirow[b]{2}{*}{ Treatments } & \multicolumn{3}{|c|}{ Seed germination $(\%)$} & \multicolumn{3}{|c|}{ Speed of germination } & \multicolumn{3}{|c|}{ Seedling length $(\mathrm{cm})$} & \multicolumn{2}{|c|}{$\begin{array}{l}\text { Microbial population } \\
\quad\left(\mathrm{cfu} \mathrm{g}^{-1} \text { of seed }\right)\end{array}$} \\
\hline & Initial & 3 MAS & Mean & Initial & 3 MAS & Mean & Initial & 3 MAS & Mean & Initial & 3 MAS \\
\hline $\mathrm{T}_{1}-$ Untreated control & 85 & 84 & 84.5 & 6.8 & 7.7 & 7.3 & 23.9 & 23.5 & 23.7 & - & - \\
\hline $\begin{array}{l}\mathrm{T}_{2}-\text { Seed soaking in Rhizobium } \\
\text { liquid culture@1:50 dilution } \\
\text { for } 3 \mathrm{~h}\end{array}$ & 95 & 94 & 94.5 & 8.3 & 8.4 & 8.4 & 26.8 & 26.9 & 26.9 & $13 \times 10^{4}$ & $12 \times 10^{4}$ \\
\hline $\begin{array}{l}\mathrm{T}_{3} \text { - Seed soaking in phosphobacteria } \\
\text { liquid culture@1:50 dilution } \\
\text { for } 3 \mathrm{~h}\end{array}$ & 89 & 88 & 88.5 & 7.9 & 8.2 & 8.1 & 26.1 & 25.0 & 25.6 & $24 \times 10^{4}$ & $20 \times 10^{4}$ \\
\hline $\begin{array}{l}\mathrm{T}_{4}-\text { Seed soaking in PPFM liquid } \\
\text { culture@ } 1: 100 \text { dilution for } 3 \mathrm{~h}\end{array}$ & 98 & 96 & 97.0 & 8.9 & 8.7 & 8.8 & 28.7 & 28.3 & 28.5 & $11 \times 10^{4}$ & $2 \times 10^{4}$ \\
\hline Mean & 91.8 & 90.5 & 91.1 & 7.9 & 8.3 & 8.2 & 26.4 & 25.9 & 26.2 & & \\
\hline SEd & \multicolumn{2}{|c|}{1.5} & 0.9 & \multicolumn{2}{|c|}{0.3} & \multicolumn{2}{|c|}{0.2} & 0.4 & \multicolumn{2}{|c|}{0.2} & \\
\hline $\mathrm{CD}(P=0.05)$ & \multicolumn{2}{|c|}{3.1} & NS & \multicolumn{2}{|r|}{0.6} & \multicolumn{2}{|c|}{ NS } & 0.8 & \multicolumn{2}{|r|}{ NS } & \\
\hline
\end{tabular}

*MAS, Months after storage.

Bacillus sp. increased root length, root mass, number of nodules and mass, as compared to control in blackgram. Similarly, PPFM inoculated with a diazotroph as individual and combined inoculant treatments has resulted in increased seedling vigour, dry matter production and yield which might be due to the increased rhizosphere population of the inoculants ${ }^{18}$. Rhizobium species besides N2-fixation, synthesizing growth hormones ${ }^{19,20}$ and methylotroph mediating cytokinin ${ }^{14}$ and IAA in the germinating seed ${ }^{15}$, have been considered the most probable means of enhanced germination and vigour. Therefore, the present study offers a pathway to combine Rhizobium and PPFM for pigeonpea seeds in which PPFM plays a role of induction of growth hormones and Rhizobium in turn helpful for nodulation and $\mathrm{N}$-fixation. However, compatibility of these microbes with seed protectants should also be considered during the seed delivery system. In this regard, the beneficial fungicide has showed antagonistic effect on the microbial populations in the pigeonpea seeds. Similarly, the survival of bio-inoculants in the chemical treated seeds was studied in many crops $^{6,7,21,22}$. Khalequzzaman ${ }^{23}$ opined that the inoculation of lentil and chickpea seeds with Rhizobium followed by bavistin treatment showed significant decrease in foot and root rot incidence and increase in plant stand and grain yield. 
RESEARCH COMMUNICATIONS

Table 5. Effect of seed infusion with microbial consortia on germination, vigour and microbial population in pigeonpea

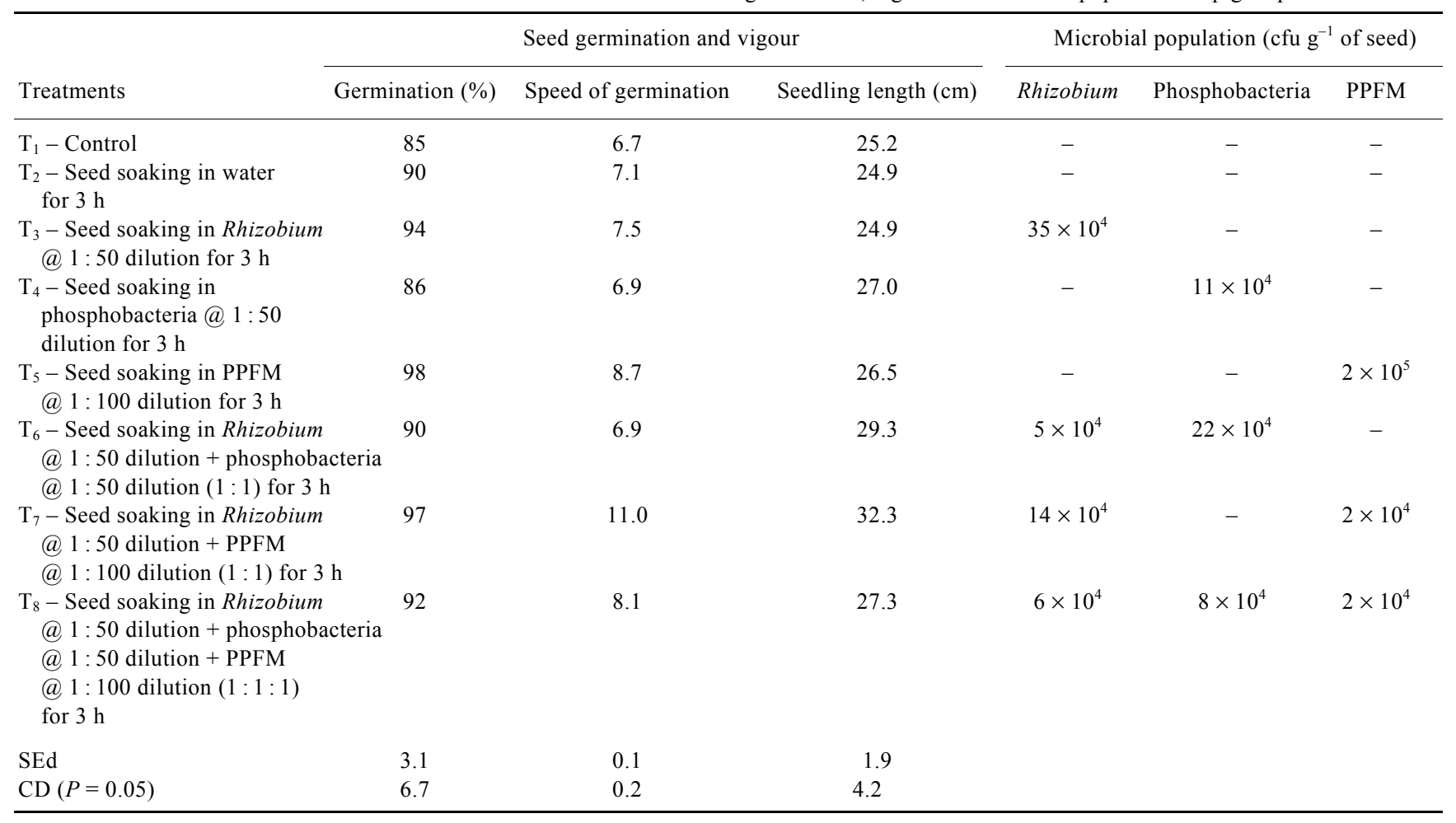

Table 6. Effect of chemical treatment on germination and microbial population in bio-inoculants-infused pigeonpea seeds

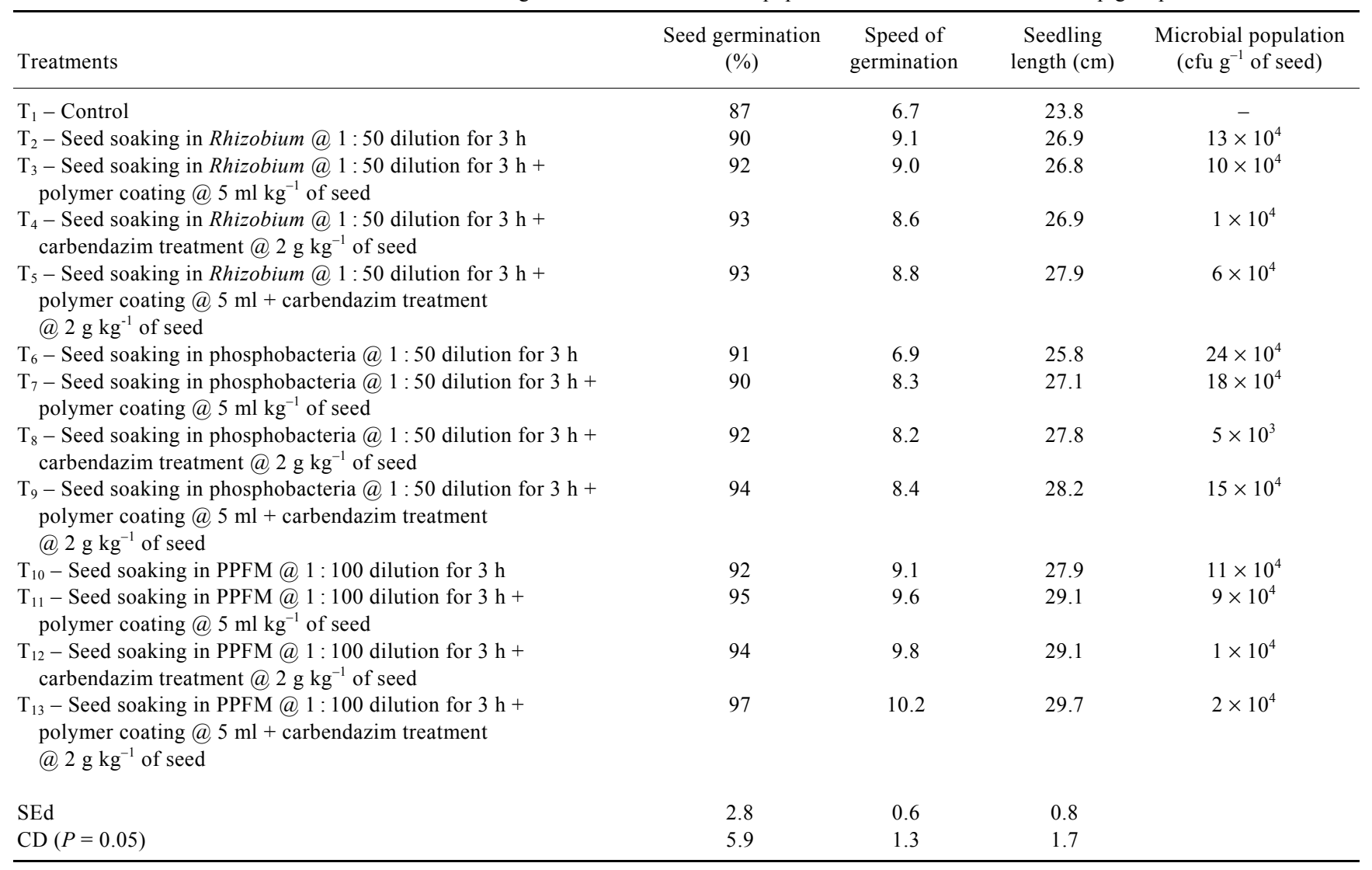


Therefore, it is concluded that the seed germination and vigour in pigeonpea seeds can be increased through infusion of liquid microbial inoculants, viz. PPFM, Rhizobium and phosphobacteria, provided, the concentration and soaking duration are taken care of. Among the bioinoculants, PPFM performed better in the germination and vigour improvement as single or co-inoculant with Rhizobium. Carbendazim treatment on the bio-inoculantinfused seeds showed reduction in the microbial population than the polymer treated seeds.

1. Datta, M. S., Banik and Gupta, R. K., Studies on the efficacy of a phytohormone producing phosphate solubilizing Bacillus firmus in augmenting paddy yield in acid soils of Nagaland. Plant Soil, 1982, 69, 365-373

2. Graham, W. L., Bennett, M. L. and Paau, A. S., Production of bacterial inoculants by direct fermentation on nutrient supplemented vermiculite. Appl. Environ. Microbiol., 1987, 53, 2138-2140.

3. Jahuri, K. S., Preparation of legume inoculants and bacterization of seed: Training Manual on Biofertilizers, Indian Agricultural Research Institute, New Delhi, India, 2001, pp. 54-62.

4. Nethery, A. A., Inoculant production with nonsterile carrier. In Expert Consultation on Legume Inoculant Production and Quality Control, FAO, Rome, 1991, pp. 43-50.

5. Hynes, R. K., Craig, K. A., Covart, D., Smith, R. S. and Rennie, R. J., Liquid rhizobial inoculants for lentil and field pea. J. Prod. Agric., 1995, 8, 547-552.

6. Bikrol, A., Saxena, N. and Singh, K., Response of glycine max in relation to nitrogen fixation as influenced by fungicides seed treatment. Afr. J. Biotechnol., 2005, 4, 667-671.

7. Dunfield, K., Siciliano, S. D. and Germida, J. J., The fungicides thiram and captan affect the phenotypic characteristics of Rhizobium leguminosarum strain $\mathrm{C} 1$ as determined by FAME and Biolog analyses. Biol. Fert. Soils, 2000, 31, 303-309.

8. ISTA, International Rules for Seed Testing. Seed Sci. Technol., 1999, 27, 30-35.

9. Maguire, J. D., Speed of germination-aid selection and evaluation for seedling emergence and vigor. Crop Sci., 1962, 2, 176-177.

10. Gomez, K. A. and Gomez, A. A., Statistical Procedures for Agricultural Research, John Wiley and Sons, New York, 1984, 2nd edn, p. 680.

11. Anitha, K. G., Enhancing seed germination of mono and dicotyledons through IAA production of PPFM. Trends Soil Sci. Plant Nutr., 2010, 1, 14-18.

12. Meena, K. K., Kumar, M., Kalyuzhnaya, M. G., Yandigeri, M. S., Singh, D. P., Saxena, A. K. and Arora, D. K., Epiphytic pinkpigmented methylotrophic bacteria enhance germination and seedling growth of wheat (Triticum aestivum) by producing phytohormone. Antonie Leeuwenhoek, 2012, 101, 777-786.

13. Nkpwatt, D. A., Martina, M., Jochen, T., Mewes, B. and Wilfried, S., Molecular interaction between Methylobacterium extorquens and seedlings: growth promotion, methanol consumption, and localization of the methanol emission site. J. Exp. Bot., 2006, 57, 4025-4032.

14. Holland, M. A. and Polacco, J. C., PPFMs and other covert contaminants: is there more to plant physiology than just plant? Annu. Rev. Plant Physiol. Plant Mol. Biol., 1994, 45, 197-209.

15. Subhaswaraj, P., Jobina, R., Parasuraman, P. and Siddhardha, B., Plant growth promoting activity of pink pigmented facultative methylotroph-Methylobacterium extorquens MM2 on Lycopersicon esculentum L. J. Appl. Biol. Biotechnol., 2017, 5(1), 4246.

16. Bakonyi, N. et al., Using biofertilizer to improve seed germination and early development of maize. Pol. J. Environ. Stud., 2013, 22, 1595-1599.

17. Qureshi, M. A., Iqbal, A., Akhtar, N., Shakir, M. A. and Khan, A., Co-inoculation of phosphate solubilizing bacteria and rhizobia in the presence of L-tryptophan for the promotion of mash bean (Vigna mungo L.). Soil Environ., 2012, 31, 47-54.

18. Raja, P. and Sundaram, S., Combined inoculation effect of pink pigmented facultative Methylobacterium (PPFM) and other bioinoculants on cotton. Asian J. Biol. Sci., 2006, 1, 39-44.

19. Zahir, Z. A., Arshad, M. and Frankenberger Jr, W. T., Plant growth promoting rhizobacteria: perspectives and application in agriculture. Adv. Agron., 2004, 81, 96-168.

20. Zahran, H. H., Rhizobia from wild legumes: diversity, taxonomy, ecology, nitrogen fixation and biotechnology. J. Biotechnol., 2001, 91, 143-153.

21. Mehta, P. V., Ramani, V. P., Patel, K. P. and Lakum, Y. C., Compatibility and feasibility evaluation of zinc application with pesticides and bio-fertilizers as seed treatments in maize. Asian J. Soil Sci., 2011, 6, 42-46.

22. Tariq, M., Hameed, S., Shahid, M., Yasmeen, T. and Ali, A., Effect of fungicides and bioinoculants on Pisum sativum. Res. Rev. J. Bot. Sci., 2016, 5, 36-40.

23. Khalequzzaman, K. M., Effect of seed treating fungicides and biofertilizer in the incidence of foot and root rot disease of lentil and chickpea. Ann. Bangladesh Agric., 2008, 12, 39-44.

ACKNOWLEDGEMENT. The authors thank the University Grants Commission (UGC), New Delhi for financial assistance to carry out this work under the major research project.

Received 14 February 2019; revised accepted 21 August 2019

doi: $10.18520 / \mathrm{cs} / \mathrm{v} 117 / \mathrm{i} 12 / 2052-2058$ 